
\title{
25 Research Square \\ CK2-mediated phosphorylation of Che-1/AATF is required for its pro-proliferative activity
}

Valeria Catena ( $\nabla$ valeria.catena@ifo.gov.it )

Regina Elena National Cancer Institute

Tiziana Bruno

National Cancer Institute: Istituto Regina Elena

Simona lezzi

National Cancer Institute: Istituto Regina Elena

Silvia Matteoni

National Cancer Institute: Istituto Regina Elena

Annalisa Salis

Universita degli Studi di Genova

Cristina Sorino

National Cancer Institute: Istituto Regina Elena

Gianluca Damonte

Universita degli Studi di Genova

Maurizio Fanciulli

National Cancer Institute: Istituto Regina Elena

\section{Research Article}

Keywords: Che-1, cancer cells, cell proliferation, histone acetylation, phosphorylation, CK2, SV40 LT

Posted Date: April 30th, 2021

DOI: https://doi.org/10.21203/rs.3.rs-459016/v1

License: (c) (1) This work is licensed under a Creative Commons Attribution 4.0 International License.

Read Full License

Version of Record: A version of this preprint was published at Journal of Experimental \& Clinical Cancer Research on July 15th, 2021. See the published version at https://doi.org/10.1186/s13046-021-02038-x. 


\section{Abstract \\ Background}

Che-1/AATF (Che-1) is an RNA polymerase II binding protein involved in several cellular processes, including proliferation, apoptosis and response to stress. We have recently demonstrated that Che 1 is able to promote cell proliferation by sustaining global histone acetylation in Multiple Myeloma (MM) cells where it interacts with histone proteins and competes with HDAC class I members for binding.

\section{Methods}

Site-directed Mutagenesis was performed to generate a Che-1 mutant (Che-1 3S) lacking three-serine residue $\left(\mathrm{Ser}^{316}, \mathrm{Ser}^{320}\right.$ and $\mathrm{Ser}^{321}$ ) in 308-325 AA region. Western blot experiments were conducted to examine the effect of depletion or over-expression of Che-1 and Che-1 3S mutant on histone acetylation, in different human cancer cell lines. Proliferation assays were assessed to estimate the change in cells number when Che-1 was over-expressed or deleted. Immunoprecipitation assays were performed to evaluate Che-1/histone $\mathrm{H} 3$ interaction when $\mathrm{Ser}^{316}, \mathrm{Ser}^{320}$ and $\mathrm{Ser}^{321}$ were removed. The involvement of CK2 kinase in Che-1 phosphorylation at these residues was analysed by in vitro kinase, 2D gel electrophoresis assays and mass spectrometry analysis.

\section{Results}

Here, we confirm that Che-1 depletion reduces cell proliferation with a concomitant general histone deacetylation in several tumor cell lines. Furthermore, we provided evidence that CK2 protein kinase phosphorylates Che-1 at Ser ${ }^{316}, \mathrm{Ser}^{320}$ and Ser ${ }^{321}$ and that these modifications are required for Che1/histone $\mathrm{H} 3$ binding. These results improve our understanding onto the mechanisms by which Che-1 regulates histone acetylation and cell proliferation.

\section{Conclusions}

Che-1 phosphorylation at $\mathrm{Ser}^{316}, \mathrm{Ser}^{320}$ and $\mathrm{Ser}^{321}$ by $\mathrm{CK} 2$ promotes the interaction with histone $\mathrm{H} 3$ and represents an essential requirement for Che-1 pro-proliferative ability.

\section{Background}

Che-1/AATF (Che-1) is a highly conserved nuclear protein overexpressed in several cancerous tissues, such as prostate, lung, colon, lymphomas as well as in multiple myeloma (MM) and in hepatocellular carcinoma (HCC), where its levels increase during disease progression (1-5). It has been previously demonstrated Che-1's involvement in important cellular activities, including proliferation, regulation of cell 
cycle, apoptosis and stress response (6-10). Many studies have highlighted the ability of Che-1 to affect the transcriptional machinery by its association with several proteins, such as RNA Polymerase II, the retinoblastoma protein $(\mathrm{Rb})$, p65 and STAT3 $(7,11,12)$. Importantly, Che-1 contains an acidic region spanning from 308 to 325 aa highly homologous to HDAC proteins and several viral oncoproteins (SV40 Large T, E1A) by which it contacts Rb, thus inhibiting its binding to HDAC 1 and promoting cell proliferation $(11,13)$. More recently, we have demonstrated that this region is required for displacing HDAC proteins from histones, increasing chromatin accessibility and MM cell proliferation (14). Che-1 half-life and functions are modulated by several post-translational modifications $(12,15,16)$, and its phosphorylation at specific serine or threonine residues has been associated with Che-1 activity in response to different stimuli, including induction of DNA damage or apoptosis $(6,17)$.

Casein kinase II (CK2) is a ubiquitous highly pleiotropic serine/threonine protein kinase present in cells in a tetrameric form consisting of two catalytic subunits (CK2a and its isoform CK2a') and two regulatory $\beta$ subunits (18). It is expressed in all tissues of eukaryotic organisms and localized in different cell compartments (19). Due to its ability to phosphorylate a wide variety of substrates, CK2 is involved in many cellular pathways, including cell growth, proliferation and survival (20-22). Several studies highlighted that CK2 is up-regulated in different tumors, including kidney, head and neck, lung and prostate (23) and it is considered an attractive target to counteract drug resistance in cancer (18). Indeed, a rising number of CK2 inhibitors have been developed and their effectiveness proven alone or in combination with conventional anticancer drugs supporting their possible application in clinical therapy (18). Moreover, several studies have demonstrated that this kinase can interact with and regulate many factors involved in chromatin remodelling $(24,25)$.

In this study, we demonstrate that Che-1 ability to promote histone acetylation and cell proliferation is not only restricted to MM cells, and that the phosphorylation at three serine residues, $\operatorname{Ser}^{316}, \mathrm{Ser}^{320}$ and $\mathrm{Ser}^{321}$, is required for these activities. Notably, we identified CK2 kinase as the enzyme responsible for these modifications. Finally, we produce evidence that also in the SV40 Large T protein the phosphorylation of conserved serine residues, within the region of homology with Che-1, is required for its activity, thus underlining the importance of these modifications in the regulation of cell proliferation.

\section{Methods}

\section{Cell culture and transfections}

Human HCT116, HeLa, 293T and U20S cell lines were cultured in Dulbecco's Modified Eagle's Medium (DMEM, Euroclone) high glucose supplemented with 10\% fetal bovine serum (FBS, Thermo Fisher Scientific), $2 \mathrm{mM}$ glutamine (Thermo Fisher Scientific) and $40 \mu \mathrm{g} / \mathrm{ml}$ gentamicin. All cell lines were cultured at $37^{\circ} \mathrm{C}$, in a humidified atmosphere with $5 \% \mathrm{CO}_{2}$. Mycoplasma contamination was periodically tested by RT-PCR analysis, using the following primers:

Forward: 5' - ACT CCT ACG GGA GGC AGC AGT A - 3' 
Transfection experiments were carried out by using Lipofectamine 3000 Transfection System (Thermo Fisher Scientific) following the manufacturer's instructions. Cells were analysed $48 \mathrm{~h}$ after transfection by western blot (WB) or immunofluorescence. Cell number and viability were assessed by Trypan Blue staining using Countess automated cell counter (Thermo Fisher Scientific).

\section{Recombinant plasmids and reagents}

Myc-Che-1 has already been described $(11,26)$. pCl-HDAC 1 was a kind gift from Dr. Sartorelli, while pSG5 Large T (pSG5 SV40 LT) plasmid was a gift from William Hahn (Addgene plasmid \#9053; http://n2t.net/addgene:9053; RRID: Addgene_9053). Myc-Che-1 3S and pSG5 SV40 LT 3S were generated by in vitro mutagenesis using the QuikChange site-directed Mutagenesis system (Agilent Technologies) following the manufacturer's instructions. PCR reactions were achieved using the following primers:

Myc- Che-1 3S:

Forward 5' - GCCCAATGCGGGAGGTGAGGAGATTGCTGGTGAAGATGATGAGC - 3'

Reverse 5' - GCTCATCATCTTCACCAGCAATCTCCTCACCTCCCGCATTGGGC - 3'

pSG5 SV 40 LT 3S:

Forward 5’ - AACCTGTTTTGCGCAGAAGAAATGCCAGCTGGTGATGATGAGGCT - 3’

Reverse 5' - AGCCTCATCATCACCAGCTGGCATTTCTTCTGCGCAAAACAGGTT - 3'

All mutations were confirmed by sequencing realized by Eurofins Genomics.

Stealth siRNA oligonucleotides targeting Che-1 (siChe-1), CSNK2A (siCK2), control sequence (siControl) and custom Che-1 3'UTR (sense 5'-CCCGCCUUUAAACGCCACAAAUAAA-3'; antisense 5'UUUAUUUGUGGCGUUUAAAGGCGGG-3') were purchased from Thermo Fisher Scientific. TBB (4,5,6,7 Tetrabromobenzotriazole) was purchased from SelleckChem. Casein kinase II (CK2 - P60105) recombinant protein and Adenosine 5'-triphosphate (ATP - P07565) were purchased from New England BioLabs.

\section{Cell extracts, immunoprecipitation and RNA isolation}

Total, cytoplasmic and nuclear extracts were prepared as previously described $(12,27,28)$. For immunoprecipitation (IP) experiments, nuclear extracts were resuspended in dilution buffer (50 mM TRIS $\mathrm{pH} 7.4,150 \mathrm{mM} \mathrm{NaCl}, 5 \mathrm{mM}$ EDTA, $10 \mathrm{mM} \mathrm{NaF}, 0.5 \%$ NP40, protease and phosphatase inhibitors). Dynabeads magnetic beads (Thermo Fisher Scientific) were incubated for $1 \mathrm{~h}$ at room temperature on a rotating wheel with the indicated antibodies. Nuclear extracts were then added to the beads and the incubation was continued for 2 additional hours. Immuno-complexes were purified by using a magnet (DynaMag-2, Thermo Fisher Scientific), the beads were washed five times with dilution buffer and eluted 
in 4X lithium dodecyl sulphate (LDS) sample buffer (Thermo Fisher Scientific) for WB analysis. Detailed information for all antibodies is provided in Supplementary Table S1. Total RNA was isolated from cells using EuroGOLD TriFast reagent (Euroclone) according to the manufacturer's instructions. The amount of RNA was measured by using NanoDrop ND-1000 Spectrophotometer (Thermo Fisher Scientific).

\section{Western blot analysis}

Samples were prepared as previously described (27), resolved on Bolt pre-cast $4-12 \%$ gels (Thermo Fisher Scientific), run using Bolt MES SDS running buffer (Thermo Fisher Scientific) and transferred onto nitrocellulose membranes. After a blocking step in $5 \%$ non fat-dried milk in phosphate-buffered saline (PBS) $-0.1 \%$ Tween, membranes were incubated with primary antibodies overnight at $4^{\circ} \mathrm{C}$. After three washes in PBS $-0.1 \%$ Tween, membranes were incubated with the appropriate HRP-linked secondary antibodies (Bio-Rad Laboratories) for $45 \mathrm{~min}$ at room temperature, washed with PBS- $0.1 \%$ Tween and analysed by chemi-luminescence (GE Healthcare Life Science). Images were acquired and quantified using Alliance Mini HD6 system by UVITEC Ltd, Cambridge, equipped with UVI1D Software (UVITEC, 14630275). Detailed information for all antibodies is provided in the Supplementary Table S1.

\section{Immunofluorescence}

Detection of both heterochromatic foci and chromatin modifications was performed as described in Bruno et al. (14). Briefly, HCT116 cells were grown on cover-lips, washed twice in PBS, fixed in 100\% methanol for $5 \mathrm{~min}$ and then permeabilized for one hour with 1\% BSA, 10\% normal goat serum, $0.3 \mathrm{M}$ glycine in $0.1 \%$ PBS-Tween. Cells were incubated with anti-H3K9me3 overnight at $4^{\circ} \mathrm{C}$ and stained $45 \mathrm{~min}$ with Alexa-Fluor-594-conjugated anti-rabbit secondary antibody (Thermo Fisher Scientific). For anti-Myc tag and anti-Che- 1 immunofluorescences, cells were fixed in $4 \%$ formaldehyde for 10 min and then permeabilized with PBS $-0.2 \%$ Triton X-100 for $5 \mathrm{~min}$ at room temperature. Cells were stained for two hours with the primary antibody, rinsed three times with PBS and stained respectively with Alexa-Fluor594-conjugated anti-mouse or with Alexa-Fluor-488-conjugated anti-rabbit secondary antibodies (Thermo Fisher Scientific) $45 \mathrm{~min}$ at room temperature. Nuclei were visualized by staining with $1 \mu \mathrm{g} / \mathrm{ml} \mathrm{Hoechst}$ dye 33258 (Sigma-Aldrich) for $10 \mathrm{~min}$. Images were acquired using a fluorescence microscope with a 40X objective (Zeiss, Germany) and processed with AxioVision 4.7.1 software.

In vitro kinase assay

GST-Che-1 fusion protein was cloned into PGEX-4T-3 vector as already described (12). For in vitro kinase assay, GST-Che-1 was incubated with or without CK2 constitutively active for $1 \mathrm{~h}$ at $30^{\circ} \mathrm{C}$ in slowly rotation on a rotating wheel in CK2 Reaction buffer (New England Biolabs) in presence of $200 \mu$ M ATP. Adding 4X LDS stopped reactions and the proteins were resolved by Bolt pre-cast $4-12 \%$ gels. The gel was stained with SimplyBlue SafeStain (Thermo Fisher Scientific) for three hours at room temperature, and bands of interest were cut and then analysed by Nano - LC Mass spectrometry (MS).

\section{Nano - LC Mass spectrometry}


After kinase assay the bands of interest were cut from the gel, de-stained, reduced, alkylated and digested with trypsin following the procedure described by Shevchenko et al. (29). The analysis of tryptic peptides was carried out by mean of nano-HPLC-MS/MS using an Ultimate 3000 nano-HPLC system and the obtained data were processed using an in-house software. The peptide pellets were re-suspended immediately before analysis and firstly loaded, from the sample loop, onto a trapping column (Acclaim PepMap C18; $2 \mathrm{~cm} \times 100 \mu \mathrm{m} \times 5 \mu \mathrm{m}, 100 \AA$ - Thermo Fisher Scientific) using the loading eluents composition ( $95-5 \% \mathrm{ACN} / \mathrm{H} 2 \mathrm{O}+0.05 \%$ trifluoroacetic acid). The separation of peptides was performed at the flow rate of $300 \mathrm{~nL} / \mathrm{min}$ and at a temperature of $35^{\circ} \mathrm{C}$ using an Easy spray column $(15 \mathrm{~cm} \times 75 \mu \mathrm{m}$ PepMap C18 $3 \mu \mathrm{m}$, Thermo Fisher Scientific). A linear gradient of solution B (95 - 5\% ACN/H2O + 0.08\% formic acid) from 4-95\% in 55 min was applied. All the analyses were performed in the positive ion mode. Single MS survey scans were performed in the Orbitrap, recording a mass window between 395 and $2000 \mathrm{~m} / \mathrm{z}$ using a maximal ion injection time of $100 \mathrm{~ms}$. The resolution was set to 70,000 and the automatic gain control was set to $3 \times 10^{6}$ ions. The experiments were performed in data-dependent acquisition mode with alternating MS and MS/MS experiments. For MS/MS analysis an isolation window of 2Da was used. CID was done with a target value of 5000 ions, a maximal ion injection time of $50 \mathrm{~ms}$, normalized collision energy of $35 \%$. Raw MS files were processed with the Thermo Scientific Proteome Discoverer software version 1.4. Peak list files were obtained by the SEQUEST search engine against the Human protein database containing both forward and reversed protein sequences. The resulting peptide hits were filtered for a maximum 1\% FDR (false discovery rate) using the percolator tool. The database search parameters were: mass tolerance precursor 20ppm, mass tolerance fragment CID $0.8 \mathrm{Da}$, dynamic modification of deamidation $(\mathrm{N}, \mathrm{Q})$, oxidation $(\mathrm{M})$ and static modification of alkylation with IAM (C). Phosphorylation of Ser were set as variable modifications. The software phosphoRS was used to validate the correct assignment of the phosphorylation sites. In any case, the option trypsin with two missed cleavages was selected (30).

\section{Identification by nano-HPLC-ESI-MS/MS}

The data obtained by the HPLC separation and MS/MS analyses, carried out on digested samples, were submitted to the SEQUEST search engine against Uniprot Human protein database using the phosphoRS tool. This approach allowed the specific identification of Tau-F of Apoptosis-antagonizing transcription factor (AATF/Che-1). Fifty-three high confidence peptides, corresponding to sequence coverage of $65.36 \%$ and high sequest score of 2391.39 , were identified. From the MS/MS analysis it was possible to identify four phosphopeptides derived from Che-1, three of which were unambiguously assigned as phosphopeptides (Table 1). In a few cases it was not possible to assign the phosphate to specific serine residue(s), thus hindering the precise localization of the phospho-residue(s). The analysis of peptides obtained from Che-1 protein untreated allowed the identification fifty-four high confidence peptides corresponding to sequence coverage of $64.64 \%$ and high sequest score of 2082.81 . As expected no phosphopeptides were found in this sample.

\section{D Gel electrophoresis}


For 2D-Gel, cell pellets were resuspended in 2-D lysis buffer (2 M thiourea, $7 \mathrm{M}$ urea, 4\% CHAPS, 1\% DTT, protease inhibitors cocktail) and sonicated. Total extracts were treated, where indicated, with Lambda Protein Phosphatase ( $(-\mathrm{PP})$ (New England BioLabs) following the protocol described in Yagamata et al., with minor modifications (31). In short, cells pellets were re-suspended and $20 \mathrm{mM} \mathrm{MnCl}_{2}$ was added to $150 \mu \mathrm{g}$ of protein extract in order to obtain a final concentration of $2 \mathrm{mM} \otimes-P P$ buffer and brought to a final volume of $20 \mu \mathrm{l}$ with deionized water. The mixture was divided into two aliquots and 200 units of $\mathbb{B}-$ PP were added to one of the aliquots. After mixing, aliquots were incubated overnight at $30^{\circ} \mathrm{C}$ under constant shaking and subsequently $100 \mu$ l of 2-D lysis buffer was added togheter with $1 \%$ sulfobetaine SB 4-7.

Isoelectric focusing was performed using $70 \mathrm{~mm}$ 4.0-7.0 linear Immobilized pH Gradient gel strips (IPG strips) (Bio-Rad Laboratories) on an electrophoresis unit (Ettan IPGphor 3; GE Healthcare Life Science). Equal amounts of proteins $(70 \mu \mathrm{g})$ were loaded by passive in-gel rehydration for 12 hours then run as follows: 1 hour at $50 \mathrm{~V}, 30 \mathrm{~min}$ at $200 \mathrm{~V}$, voltage gradient $30 \mathrm{~min}$ up to 1,000 V, 20 min at 1,000 V, voltage gradient $30 \mathrm{~min}$ up to $5,000 \mathrm{~V}$ and 1 hour at 5,000 V. Before performing the 2 nd electrophoresis dimension, IPG strips were equilibrated for $15 \mathrm{~min}$ at room temperature in $1 \%$ DTT to reduce the proteins, and sulfhydryl groups were subsequently derivatized using $4 \%$ iodoacetamide (both solutions were prepared in $50 \mathrm{mM}$ Tris, $\mathrm{pH} 8.8,6 \mathrm{M}$ urea, $30 \%$ glycerol, $2 \%$ SDS, and $2 \%$ bromophenol blue) for $15 \mathrm{~min}$. Strips were transferred to $1.0-\mathrm{mm}$-thick 4-12\% pre-casted polyacrylamide mini-gels (Thermo Fisher Scientific) for the 2nd electrophoresis dimension and then gels were run at $130 \mathrm{~V}$ for $2 \mathrm{~h} .2 \mathrm{D}$ gels were then transferred onto PVDF filters.

\section{In vitro GST pull down assay}

Full length $\mathrm{H} 3$ open reading frame was cloned into EcoRI/Xhol sites of pGEX-4T-1 in order to generate GST-H3 fusion protein. GST-H3 or GST control proteins were prepared following standard procedures and used for in vitro binding assay. Briefly, GST proteins were pre-incubated with Che-1 308-325, Che-1 $3 S$ or control peptides (Biomatik Corporation) for $1 \mathrm{~h}$ at $4^{\circ} \mathrm{C}$ on a rotating wheel in interaction buffer $(20 \mathrm{mM}$ Tris $\mathrm{pH} 7.9,300 \mathrm{mM} \mathrm{NaCl}, 0.2 \mathrm{mM}$ EDTA, $0.1 \% \mathrm{NP} 40,10 \mu \mathrm{g} / \mathrm{ml} \mathrm{BSA}$ ). Total extracts from HCT116 cells over-expressing pCl-HDAC 1 were then added to the GST/peptides complexes and the incubation was continued for three additional hours. Samples were eluted in 4X LDS sample buffer by heating for $10 \mathrm{~min}$ at $70^{\circ} \mathrm{C}$ and then subjected to WB analysis. Peptides sequence commercially synthesized are:

Control: LKGAKPIRPVVVKAPPA

Che-1 308-325: DGTKPNAGSEEISSEDDEL

Che-1 3S: DGTKPNAGAEEIAAEDDEL

\section{Micrococcal nuclease assay}

Micrococcal nuclease (MNase) assay was performed using the protocol described in Zaret et al. (32). Briefly, HCT116 cells were seeded in $100 \mathrm{~mm}$ plate and transiently transfected with Myc-Che- $1 \mathrm{wt}$, Myc- 
Che-1 $3 \mathrm{~S}$ or empty vector. $24 \mathrm{~h}$ post transfection cells were subjected to the protocol described in Bruno et al. (14).

\section{Quantification and Statistical Analysis}

Data are presented as the mean of three independent experiments \pm standard deviation (SD). Statistical analyses were performed using R software. Two-tailed Student's $t$-tests with Benjamini-Hochberg correction were performed to compare one parameter between two groups. For the multiple group comparison, one-way ANOVA with Tukey HSD test was used. $P<0.05$ was considered significant.

Statistical significance is indicated by asterisks as follows: ${ }^{*} P<0.05,{ }^{\star \star} P<0.01,{ }^{\star \star \star} P<0.005$, ${ }^{\star \star \star \star} P<$ 0.001, n.s. $=$ not significant .

\section{Results}

\section{Che-1 depletion reduces proliferation in several cancer cell lines}

As previously observed, Che-1 displayed to have a key role in MM cells proliferation (14). To assess whether this effect could also be observed in other tumor cells of different origins, we performed cell proliferation analysis in HCT116, HeLa, 293T and U2OS cells, depleted or not for Che-1 expression. As shown in Fig. 1A, Che-1 inhibition produced a significant reduction of cell proliferation when compared to control cells in all tested cell lines. Since Che-1 depletion induces heterochromatin accumulation in MM cells (14), we evaluated whether this was a general phenomenon. To this aim, we analysed the formation of heterochromatin foci by immunofluorescence in HCT116 cells, observing that Che-1 depleted cells exhibited a strong increase of Hoechst-positive heterochromatic foci (from 9 to 32 foci/cell) (Fig. 1B). Consistent with these findings, WB analysis showed that Che-1 knockdown produced a significant increase of H3K9me3 levels, an important hallmark of heterochromatin (Fig. 1C). These results were confirmed through immunofluorescence experiments in which a marked increase of H3K9me3 positive dots was observed following Che-1 downregulation (Fig. 1D). It has been shown that Che-1 depletion produces a global reduction of histone acetylation in MM cells (14). To extend these findings, we performed WB analyses in several tumor cell lines depleted or not for Che-1 expression, observing that the loss of Che-1 expression produced a strong reduction in both $\mathrm{H} 3$ and $\mathrm{H} 4$ histone acetylation (Fig. 1E). In line with the obtained results, we observed a reduction of about $50 \%$ of total RNA in Che-1 depleted cells when compared to control cells (Fig. 1F). Overall, these findings reinforce the role of Che-1 in sustaining cell proliferation by maintaining an active state of chromatin.

\section{Che- 1 is highly phosphorylated}

Che-1 affects multiple cellular processes thanks to its ability to interact with several transcription factors $(7,11)$. These interactions are modulated by post-translational modifications in response to different stimuli, including phosphorylation at specific serine or threonine residues (6). In this context, we have 
previously shown that Che- 1 contains a highly acidic sequence (308-325 aa) involved in Che-1-histone binding. Indeed, Che-1 mutant lacking this region was no longer able to bind histone H3 (14). Interestingly, in this region are present three highly conserved serine residues (in bold; Fig. 2A), whose phosphorylation has been reported by many phospho-proteomic studies (33-35). To investigate the relevance of this Che1 region, we performed a 2D gel electrophoresis analysis of total extracts from HeLa cells treated or not with lambda phosphatase ( $\lambda$-PP), and observed that Che-1 is constitutively and highly phosphorylated (Fig. 2B). Next, we produced a Che-1 mutant (Che-1 3S) in which the serine residues in position 316, 320 and 321 were replaced with glycine or alanine (Fig. 2C). A bidimensional gel electrophoresis analysis of HeLa cells over-expressing Che-1 wild type (Myc-Che-1) or 3S mutant (Myc-Che-1 3S) showed that this mutant was less phosphorylated than wild-type (wt) protein (Fig. 2D), indicating that these residues contribute significantly to total protein phosphorylation.

Next, we started to characterize the functional role of these modifications investigating whether the $3 \mathrm{~S}$ mutant had a different cellular localization. Immunofluorescence experiments showed that the mutant retained the peculiar nuclear signal of the wt protein (Fig. 2E). In agreement with these data, a subcellular fractionation of HCT116 cells transiently transfected with Myc-Che-1 wt or 3S mutant, detected a strong accumulation in the nuclear fraction of both molecules (Fig. 2F).

\section{Che-1 phosphorylation is required for its pro-proliferative ability}

The data shown above demonstrate that three serine residues contained in the 308-325 region are phosphorylated. This region plays an important role in Che-1's functions $(11,14)$. To shed light on the relevance of these phosphorylations, we evaluated the effect of the over-expression of Myc-Che- 1 wt or 3S mutant. As shown in Fig. 3A and Supplementary Fig. 1A, Myc-Che-1 3S over-expression in HCT116 cells did not induce cell proliferation when compared to Myc-Che-1 wt. These results were confirmed in MM cells (KMS27 cells) and in other cell lines (Supplementary Figs. 1B-D). The relevance of these three serine residues in the pro-proliferative role of Che-1 was further confirmed by evaluating the effect of the overexpression of these molecules on the levels of cyclin B1. In fact, as shown in Fig. 3B, only Myc-Che-1 wt was able to increase the levels of this protein. Next, we verified whether the over-expression of MycChe-1 3 S had any impact on global transcription by measuring the level of total RNA. As shown in Fig. 3C, the Myc-Che-1 3S mutant was completely unable to activate transcription. In order to evaluate whether Che-1 phosphorylation in $\mathrm{Ser}^{316}, \mathrm{Ser}^{320}$ and $\mathrm{Ser}^{321}$ was required to sustain histone acetylation, we analysed the effect of Myc-Che-1 wt or 3S mutant over-expression on $\mathrm{H} 3$ and $\mathrm{H} 4$ histone acetylation. As shown in Fig. 3D, Myc-Che-1 3S mutant showed no effect on histone acetylation and remarkably it was unable to rescue the effects of endogenous Che-1 depletion (Fig. 3E). These results prompted us to investigate the ability of the Che-1 $3 \mathrm{~S}$ mutant to interact with histone $\mathrm{H} 3$. To this aim, we performed coimmunoprecipitation experiments with anti-Myc antibody using nuclear extracts from HCT116 cells overexpressing Myc-Che-1 wt or its 3S mutant. As shown in Fig. 3F and in Supplementary Fig. 1E, the replacement of the three serine residues prevented Che-1/histone $\mathrm{H} 3$ interaction. Moreover, an in vitro competition assay demonstrated that only the Che-1 308-325 peptide containing phosphorylated serines 
was able to displace HDAC 1 from histone H3 (Fig. 3G). Notably, KMS27 cells transfected with Che-1 308-325, but not with Che-1 3 S peptide, displayed a reduction in cell proliferation (Supplementary Fig. 1F). Consistent with these results, an MNase susceptibility assay performed in HCT116 cells transiently transfected with Myc-Che-1 wt or 3S mutant demonstrated that the mutant overexpression produced a more compacted chromatin structure (Fig. $3 \mathrm{H}$ ).

Overall, these results clearly indicate that the presence of the three serine residues in 308-325 aa region represents an essential requirement for Che- 1 activity, promoting the Che-1/histone binding and histone acetylation.

\section{Che-1 and SV40 Large T antigen display similar functions}

SV40 LT is a multifunctional viral oncoprotein implicated in a wide range of cellular processes including transcriptional activation and repression, stimulation of the cell cycle and cell transformation (36). Interestingly, SV40 LT expression increases global histone acetylation and CREB-binding protein (CBP) histone acetyltransferase (HAT) activity (36). As already described, Che-1 308-325 aa region is highly conserved among mammalian species and shared with several viral and HDAC 1-3 proteins (11). Among viral oncoproteins, SV40 Large T antigen (SV40 LT) contains three particular serine residues, in position 106, 110 and 111, corresponding to those of Che-1 (in red; Fig. 4A). These observations prompted us to verify whether SV40 LT phosphorylation on $\operatorname{Ser}^{106}, \operatorname{Ser}^{110}$ and $\operatorname{Ser}^{111}$ residues, was required for its ability to regulate cellular proliferation. To this aim, we produced a SV40 LT mutant (SV40 LT 3S) in which $\operatorname{Ser}^{106}$, Ser $^{110}$ and Ser $^{111}$ residues were replaced with alanine or glycine (Fig. 4B). Notably, HCT116 cells over-expressing SV40 LT 3S mutant didn't exhibit the induction of cellular proliferation observed in SV40 LT wt cells (Fig. 4C). Furthermore, this mutant was unable to induce the histone acetylation increase observed in cells transfected with SV40 LT wt (Fig. 4D). Since Che-1 phosphorylation in the 308-325 region is required for the interaction with histone H3 (Fig. 3F), we evaluated whether SV4O LT wt was also able to interact with histone $\mathrm{H} 3$ and whether phosphorylation of $\operatorname{Ser}^{106}, \operatorname{Ser}^{110}$ and $\operatorname{Ser}^{111}$ residues was involved in this binding. To this aim, we performed co-immunoprecipitation experiments with anti-SV40 antibody in nuclear extracts from HCT116 transiently transfected with SV40 LT wt or its 3S mutant. Remarkably, we observed that the SV40 LT wt protein showed the ability to bind histone H3 whereas, in line with results obtained with Che-1, the mutant lost this ability (Fig. 4E).

Taken together, these data reinforce the importance of this highly acidic region in several proteins for binding to histones and cell proliferation.

\section{CK2 phosphorylates Che-1}

Next, we focused on identifying the kinase responsible for the phosphorylation of Che-1 in Ser ${ }^{316}, \mathrm{Ser}^{320}$ and $\mathrm{Ser}^{321}$ residues. Previous studies have demonstrated that protein kinase Casein Kinase II (CK2) phosphorylates SV40 LT at Ser ${ }^{111}$ and $\operatorname{Ser}^{112}$ producing an augment of 50-fold of the rate of nuclear import of its protein (37). In the Che-1 308-325 aa region, two consecutive CK2 consensus sites (S/T-x-x$\mathrm{D} / \mathrm{E} / \mathrm{pS})$ are located in the proximity of its NLS $(38,39)$. To investigate whether Che-1 could be a new CK2 
target, we started testing if Che-1 physically interacts with CK2. As shown in Fig. 5A and Supplementary Fig. 2A, immunoprecipitation experiments revealed that Che-1 co-precipitates with CK2. Next, we analysed the role of CK2 in Che-1 phosphorylation by performing 2D-electrophoresis experiments in HeLa cells treated or not with the CK2 inhibitor, 4,5,6,7-Tetrabromobenzotriazole (TBB). From this experiment, we observed a strong decrease in Che-1 phosphorylation in the absence of CK2 kinase activity (Fig. 5B and Supplementary Fig. 2B). Consistent with these findings, the depletion of CK2 expression by using specific siRNA stealth oligonucleotides (siCK2) induced a remarkable reduction of Che-1 phosphorylation when compared to control cells (Fig. $5 \mathrm{C}$ and Supplementary Fig. 2C). Next, we sought to determine the possibility that Che-1 was a direct substrate of CK2. To this aim, GST-Che-1 fusion protein was incubated or not with recombinant CK2 enzyme and subjected to in vitro kinase assay. The kinase reaction products were analysed by nano-HPLC-MS/MS and the results obtained were then submitted to the SEQUEST search engine against the Uniprot Human protein database using the phosphoRS tool. This approach allowed identifying four Che- 1 phosphopeptides, including those containing $\mathrm{Ser}^{316}, \mathrm{Ser}^{320}$ and $\mathrm{Ser}^{321}$ (Table 1 and Supplementary Fig. 2D). As expected, no phosphopeptides were detected when Che-1 was incubated in the absence of CK2 (data not shown).

Next, we verified the effect of CK2 silencing on Che-1 cellular localization by performing immunofluorescence experiments. As shown in Fig. 5D and Supplementary Fig. 2E, the absence of protein kinase does not affect nuclear localization of Che-1. Then, in order to confirm the role of these phosphorylations in Che-1 activity, we tested whether the absence of CK2 could affect Che-1/histone H3 binding. Co-immunoprecipitation experiments in HCT116 cells treated or not with TBB, demonstrated that the inhibition of CK2 kinase activity induces a drastic reduction of histone $\mathrm{H} 3$ interaction with Che-1 (Supplementary Fig. 2F), and similar results were obtained following CK2 depletion (Fig. 5E).

Altogether, these data clearly demonstrate that CK2 phosphorylates Che-1 at $\mathrm{Ser}^{316}, \mathrm{Ser}^{320}$ and $\mathrm{Ser}^{321}$, and that these modifications are essential for Che-1 activity.

\section{Discussion}

Thanks to its ability to interact with several transcription factors, Che-1 represent an important cofactor involved in multiple cellular processes $(7,11,12)$. In this context, post-translational modifications play a crucial role in controlling Che-1 co-transcriptional activity in response to different stimuli $(6,15)$. We recently described Che-1 involvement in MM proliferation by affecting chromatin structure and sustaining global gene transcription. Also, we demonstrated that 308-325 aa region of Che- 1 is required for these activities (14).

In this study, we extended these results, confirming the roles played by Che-1 in the control of cellular proliferation and chromatin remodelling, in other cancer cell lines. More importantly, our results highlighted that the phosphorylations at $\mathrm{Ser}^{316}, \mathrm{Ser}^{320}$ and $\mathrm{Ser}^{321}$, contained in the Che-1 308-325 aa region, are essential for Che-1 activity. Consistent with these findings, a Che-1 mutant lacking these 
residues (Che-1 3S) is unable to bind histones and to regulate chromatin structure and transcription. Finally, we identified CK2 as the protein kinase responsible for Che-1 phosphorylation (Fig. 6).

The relevance of 308-325 aa region in controlling Che-1's functions has already been highlighted (11, 14). This region is highly conserved among several species and is present in many proteins involved in transcriptional regulation $(11,13)$. In addition, phosphoproteomic studies have demonstrated $\mathrm{Ser}^{316}$, $\mathrm{Ser}^{320}$ and $\mathrm{Ser}^{321}$ phosphorylation in all species analysed and that this modification is strongly abolished by the inhibition of different protein kinases implicated in cell cycle control (33-35). In this study, we demonstrate the functional relevance of these modifications, since the replacement of these three serines produces a protein unable to modulate chromatin structure and gene transcription. This mutant does not bind histone proteins, and presumably serine phosphorylation is necessary to increase the acidic components of this region, thus enhancing the binding with the basic structure of histones. The importance of this region and its modifications is further confirmed by the analysis of the SV40 Large T protein (SV40 LT). This oncoprotein contains a region of high homology with the 308-325 aa region of Che-1, and also it is able to bind histones, sustaining their acetylation, and to activate cell proliferation by regulating gene transcription (36). By producing a SV40 LT mutant protein, we were able to demonstrate that even in this case, the phosphorylation of these serines is necessary for the functionality of the protein, thus supporting the hypothesis of a close correlation between viral oncoproteins and Che- 1 .

Finally, we demonstrated that Che-1 is phosphorylated by CK2 at $\mathrm{Ser}^{316}, \mathrm{Ser}^{320}$ and $\mathrm{Ser}^{321}$ in proliferating cells although in which phase of the cycle these modifications occurs, remain to be clarified. CK2 is highly expressed in several tumor cells, and its activity sustains cell proliferation (20-23), therefore it is considered an attractive target to counteract drug resistance in cancer. Indeed, specific CK2 inhibitors have shown proven efficacy on tumor cell proliferation and drug resistance (18). Since Che-1 silencing is able to induce apoptosis or cell cycle arrest and sensitize MM cells to treatment with proteasome and BET inhibitors $(2,14)$, targeting Che-1 by using CK2 inhibitors could represent an interesting novel therapeutic approach.

\section{Conclusion}

In conclusion, our findings clearly confirmed the global pro-proliferative ability of Che- 1 in tumor cells. We highlighted the relevance of the phosphorylation at $\mathrm{Ser}^{316}, \mathrm{Ser}^{320}$ and $\mathrm{Ser}^{321}$ for its functions and identified CK2 as the protein kinase responsible for this modification.

\section{Abbreviations}

MM

multiple myeloma;

$\mathrm{HCC}$

hepatocellular carcinoma;

CK2 
Casein Kinase Il;

SV40 LT

Simian virus 40 Large T;

$\mathrm{Rb}$

retinoblastoma;

WB

western blot;

IP

immunoprecipitation;

MNase

Micrococcal nuclease;

MS

Mass Spectrometry;

ATP

Adenosine 5'-triphosphate;

$\lambda$-PP

lambda protein phosphate;

wt

wild type;

Ser

serine;

aa

aminoacid;

NLS

nuclear localization signal.

\section{Declarations}

\section{FUNDINGS}

This work was supported by the Italian Association for Cancer Research (15255 to M.F.) and Ministry of Health (RF-2019-12368737 to M.F).

\section{AUTHOR'S CONTRIBUTIONS}

V.C., T.B and S.I. performed most of the experiments and analysed data; S.M. performed 2D gel electrophoresis assays; C.S. conducted immunofluorescence analyses; A.S. performed MS/MS analyses; G.D. participated in data analyses; M.F. conceived the projects, obtained funding and supervised the experiments; M.F and V.C. discussed the experiments and wrote the manuscript. 
The authors declare that they have no known competing financial interests or personal relationships that could have appeared to influence the work reported in this paper.

\section{ACKNOWLEDGEMENT}

We thank Mrs. Tania Merlino for the English language revision of the manuscript and Dr. Francesca Fabretti for technical and scientific support.

\section{References}

1. Bacalini MG, Tavolaro S, Peragine N, Marinelli M, Santangelo S, Del Giudice I, et al. A subset of chronic lymphocytic leukemia patients display reduced levels of PARP1 expression coupled with a defective irradiation-induced apoptosis. Exp Hematol. 2012;40(3):197-206 e1.

2. Desantis A, Bruno T, Catena V, De Nicola F, Goeman F, lezzi S, et al. Che-1-induced inhibition of mTOR pathway enables stress-induced autophagy. EMBO J. 2015;34(9):1214-30.

3. Kaul D. Cellular AATF gene: armour against HIV-1. Indian J Biochem Biophys. 2007;44(5):276-8.

4. Uhlen M, Fagerberg L, Hallstrom BM, Lindskog C, Oksvold P, Mardinoglu A, et al. Proteomics. Tissuebased map of the human proteome. Science. 2015;347(6220):1260419.

5. Kumar DP, Santhekadur PK, Seneshaw M, Mirshahi F, Tuculescu CU, Sanyal AJ. A Novel Regulatory Role of Apoptosis Antagonizing Transcription Factor in the Pathogenesis of NAFLD and HCC. Hepatology. 2018.

6. lezzi S, Fanciulli M. Discovering Che-1/AATF: a new attractive target for cancer therapy. Front Genet. 2015;6:141.

7. Ishigaki S, Fonseca SG, Oslowski CM, Jurczyk A, Shearstone JR, Zhu LJ, et al. AATF mediates an antiapoptotic effect of the unfolded protein response through transcriptional regulation of AKT1. Cell Death Differ. 2010;17(5):774-86.

8. Caliskan G, Baris IC, Ayaydin F, Dobson MJ, Senarisoy M, Boros IM, et al. Che1/AATF interacts with subunits of the histone acetyltransferase core module of SAGA complexes. PLoS One. 2017;12(12):e0189193.

9. Welcker D, Jain M, Khurshid S, Jokic M, Hohne M, Schmitt A, et al. AATF suppresses apoptosis, promotes proliferation and is critical for Kras-driven lung cancer. Oncogene. 2018;37(11):1503-18.

10. Bruno T, Valerio M, Casadei L, De Nicola F, Goeman F, Pallocca M, et al. Che-1 sustains hypoxic response of colorectal cancer cells by affecting Hif-1 alpha stabilization. J Exp Clin Canc Res. 2017;36.

11. Bruno T, De Angelis R, De Nicola F, Barbato C, Di Padova M, Corbi N, et al. Che-1 affects cell growth by interfering with the recruitment of HDAC1 by Rb. Cancer Cell. 2002;2(5):387-99.

12. Bruno T, De Nicola F, lezzi S, Lecis D, D'Angelo $C$, Di Padova $M$, et al. Che-1 phosphorylation by ATM/ATR and Chk2 kinases activates p53 transcription and the G2/M checkpoint. Cancer Cell. 2006;10(6):473-86. 
13. Di Padova M, Bruno T, De Nicola F, lezzi S, D'Angelo C, Gallo R, et al. Che-1 arrests human colon carcinoma cell proliferation by displacing HDAC1 from the p21WAF1/CIP1 promoter. J Biol Chem. 2003;278(38):36496-504.

14. Bruno T, De Nicola F, Corleone G, Catena V, Goeman F, Pallocca M, et al. Che-1/AATF-induced transcriptionally active chromatin promotes cell proliferation in multiple myeloma. Blood Adv. 2020;4(22):5616-30.

15. De Nicola F, Catena V, Rinaldo C, Bruno T, lezzi S, Sorino C, et al. HIPK2 sustains apoptotic response by phosphorylating Che-1/AATF and promoting its degradation. Cell Death Dis. 2014;5:e1414.

16. Hopker K, Hagmann H, Khurshid S, Chen S, Hasskamp P, Seeger-Nukpezah T, et al. AATF/Che-1 acts as a phosphorylation-dependent molecular modulator to repress p53-driven apoptosis. EMBO J. 2012;31(20):3961-75.

17. Bruno T, lezzi S, Fanciulli M. Che-1/AATF: A Critical Cofactor for Both Wild-Type- and Mutant-p53 Proteins. Front Oncol. 2016;6:34.

18. Borgo C, Ruzzene M. Role of protein kinase CK2 in antitumor drug resistance. J Exp Clin Canc Res. 2019;38.

19. Seldin DC, Lou DY, Toselli P, Landesman-Bollag E, Dominguez I. Gene targeting of CK2 catalytic subunits. Mol Cell Biochem. 2008;316(1-2):141-7.

20. Homma MK, Homma Y. Cell cycle and activation of CK2. Mol Cell Biochem. 2008;316(1-2):49-55.

21. Coccetti P, Tripodi F, Tedeschi G, Nonnis S, Marin O, Fantinato S, et al. The CK2 phosphorylation of catalytic domain of Cdc34 modulates its activity at the $G(1)$ to $S$ transition in Saccharomyces cerevisiae. Cell Cycle. 2008;7(10):1391-401.

22. Li HC, Liu XS, Yang XM, Wang YM, Wang Y, Turner JR, et al. Phosphorylation of CLIP-170 by PIk1 and CK2 promotes timely formation of kinetochore-microtubule attachments. Embo Journal. 2010;29(17):2953-65.

23. Chua MMJ, Ortega CE, Sheikh A, Lee M, Abdul-Rassoul H, Hartshorn KL, et al. CK2 in Cancer: Cellular and Biochemical Mechanisms and Potential Therapeutic Target. Pharmaceuticals-Base. 2017;10(1).

24. Deplus R, Blanchon L, Rajavelu A, Boukaba A, Defrance M, Luciani J, et al. Regulation of DNA Methylation Patterns by CK2-Mediated Phosphorylation of Dnmt3a. Cell Rep. 2014;8(3):743-53.

25. Wu SY, Lee AY, Lai HT, Zhang H, Chiang CM. Phospho Switch Triggers Brd4 Chromatin Binding and Activator Recruitment for Gene-Specific Targeting. Mol Cell. 2013;49(5):843-57.

26. Fanciulli M, Bruno T, Di Padova M, De Angelis R, lezzi S, lacobini $C$, et al. Identification of a novel partner of RNA polymerase II subunit 11, Che-1, which interacts with and affects the growth suppression function of Rb. FASEB J. 2000;14(7):904-12.

27. Sorino C, Catena V, Bruno T, De Nicola F, Scalera S, Bossi G, et al. Che-1/AATF binds to RNA polymerase I machinery and sustains ribosomal RNA gene transcription. Nucleic Acids Res. 2020;48(11):5891-906. 
28. Sorino C, Bruno T, Desantis A, Di Certo MG, lezzi S, De Nicola F, et al. Centrosomal Che-1 protein is involved in the regulation of mitosis and DNA damage response by mediating pericentrin (PCNT)dependent Chk1 protein localization. J Biol Chem. 2013;288(32):23348-57.

29. Marques-Santos LF, Grassi G, Bergami E, Faleri C, Balbi T, Salis A, et al. Cationic polystyrene nanoparticle and the sea urchin immune system: biocorona formation, cell toxicity, and multixenobiotic resistance phenotype. Nanotoxicology. 2018;12(8):847-67.

30. Taus T, Kocher T, Pichler P, Paschke C, Schmidt A, Henrich C, et al. Universal and Confident Phosphorylation Site Localization Using phosphoRS. Journal of Proteome Research. 2011;10(12):5354-62.

31. Yamagata A KD, Takeda Y, Miyamoto Y, Okada K, Inamatsu M, Yoshizato K. Mapping of phosphorylated proteins on two-dimensional polyacrylamide gels using protein phosphatase. Proteomics. 2002;2(9):1267-76.

32. Zaret K. Micrococcal nuclease analysis of chromatin structure. Curr Protoc Mol Biol. 2005;Chapter 21:Unit 211.

33. Alayev A, Doubleday PF, Berger SM, Ballif BA, Holz MK. Phosphoproteomics reveals resveratroldependent inhibition of Akt/mTORC1/S6K1 signaling. J Proteome Res. 2014;13(12):5734-42.

34. Dephoure N, Zhou C, Villen J, Beausoleil SA, Bakalarski CE, Elledge SJ, et al. A quantitative atlas of mitotic phosphorylation. Proc Natl Acad Sci U S A. 2008;105(31):10762-7.

35. Santamaria A, Wang B, Elowe S, Malik R, Zhang F, Bauer M, et al. The Plk1-dependent phosphoproteome of the early mitotic spindle. Mol Cell Proteomics. 2011;10(1):M110 004457.

36. Valls E, de la Cruz X, Martinez-Balbas MA. The SV40 T antigen modulates CBP histone acetyltransferase activity. Nucleic Acids Res. 2003;31(12):3114-22.

37. Rihs HP, Jans DA, Fan H, Peters R. The Rate of Nuclear Cytoplasmic Protein-Transport Is Determined by the Casein Kinase-li Site Flanking the Nuclear-Localization Sequence of the Sv40 T-Antigen. Embo Journal. 1991;10(3):633-9.

38. Lindfors K, Halttunen T, Nupponen N, Vihinen M, Visakorpi T, Maki M, et al. Identification of a novel transcription factor-like gene repressed during TGF-beta induced human intestinal epithelial cell differentiation. Gastroenterology. 2000;118(4):A289-A.

39. Xiao CY, Jans P, Jans DA. Negative charge at the protein kinase CK2 site enhances recognition of the SV40 large T-antigen NLS by importin: effect of conformation. Febs Lett. 1998;440(3):297-301.

\section{Tables}

Table 1. CK2-phosphorylated Che-1 residues identified by nano-LC-mass spectrometry. MS/MS analysis of in vitro phosphorylation assay showing Che-1 phosphopeptides including Ser ${ }^{316}$, Ser $^{320}$ and Ser $^{321}$. For each peptide the following details are reported: aminoacid sequence, phosphorylation site(s); pRS peptide score (cumulative binomal probability that the observed match is a random events); pRS isoform probability (probability that the isoform is correct); pRS site probability (probability 
of each site being truly phosphorylated); $q$-value (minimal false discovery rate at which the identification is considered correct); PEP score (probability that the peptide-spectrum match is incorrect); number of missed-cleavages.

\begin{tabular}{|c|c|c|c|c|c|c|c|c|}
\hline Sequence & Modifications & Phosposite & $\begin{array}{l}\text { pRS } \\
\text { Score }\end{array}$ & $\begin{array}{c}\text { pRS } \\
\text { Probability }\end{array}$ & pRS Site Probabilities & $\begin{array}{c}\text { q- } \\
\text { Value }\end{array}$ & PEP & $\begin{array}{c}\text { \# Missed } \\
\text { Cleavages }\end{array}$ \\
\hline TPGFSVQSISDFEK & S10(Phospho) & S255 & 228 & $100.0 \%$ & $S(5): 0.0 ; S(8): 0.0 ; S(10): 100.0$ & $\overline{0}$ & $\begin{array}{r}0,0000182 \\
8\end{array}$ & $\overline{0}$ \\
\hline $\begin{array}{l}\text { YLVDGTKPNAGSEEISSEDDELVEEK } \\
\end{array}$ & S17(Phospho) & $\mathbf{S 3 2 0 / \mathrm { S321 }}$ & $\overline{144}$ & $50.0 \%$ & $\mathrm{~S}(12): 0.0 ; \mathrm{S}(16): 50.0 ; \mathrm{S}(17): 50.0$ & $\overline{0}$ & $\begin{array}{r}0,0000427 \\
9\end{array}$ & $\overline{0}$ \\
\hline YLVDGTKPNAGSEEISSEDDELVEEKK & S12(Phospho) & S316 & 124 & $95.9 \%$ & $\mathrm{~S}(12): 95.9 ; \mathrm{S}(16): 2.1 ; \mathrm{S}(17): 2.1$ & 0 & 0,0009297 & 1 \\
\hline SLVGLqEELLFqYPDTR & $\begin{array}{l}\text { S1(Phospho); } \\
\text { Q6(Deamidated); } \\
\text { Q12(Deamidated) }\end{array}$ & S288 & 95 & $100 \%$ & $\mathrm{~S}(1): 100.0$ & 0 & 0,0005038 & $\overline{0}$ \\
\hline
\end{tabular}

\section{Figures}


A

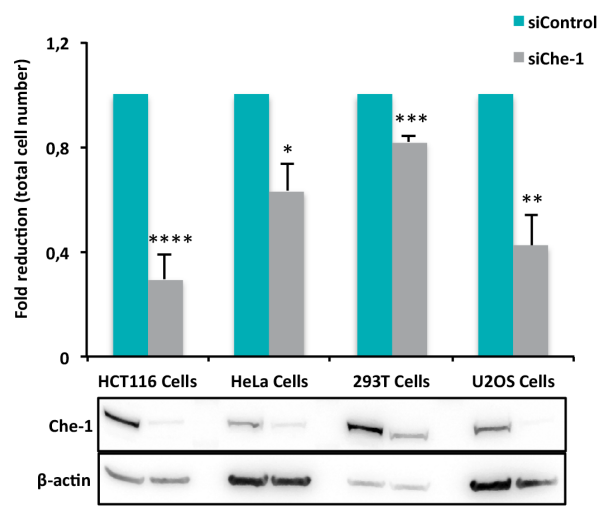

C

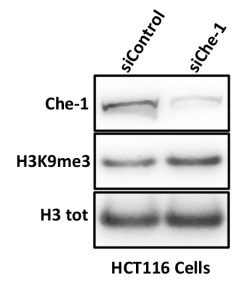

$E$

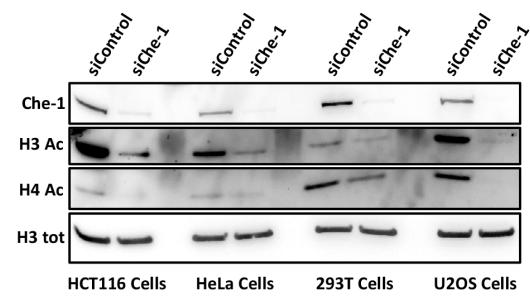

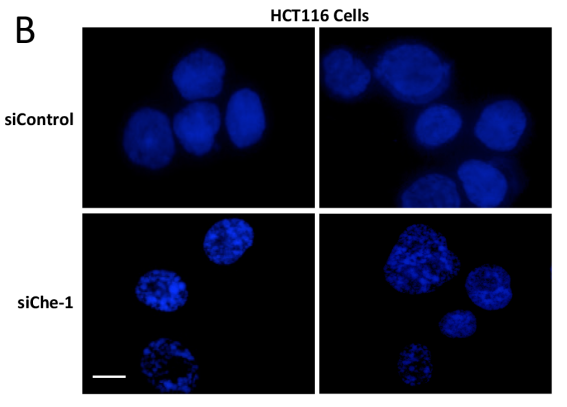
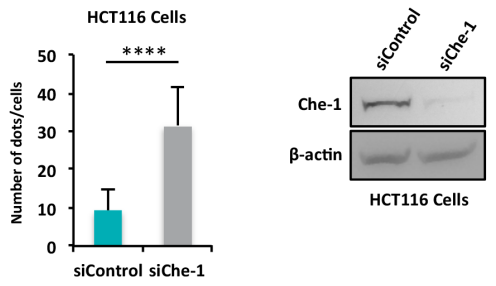

D
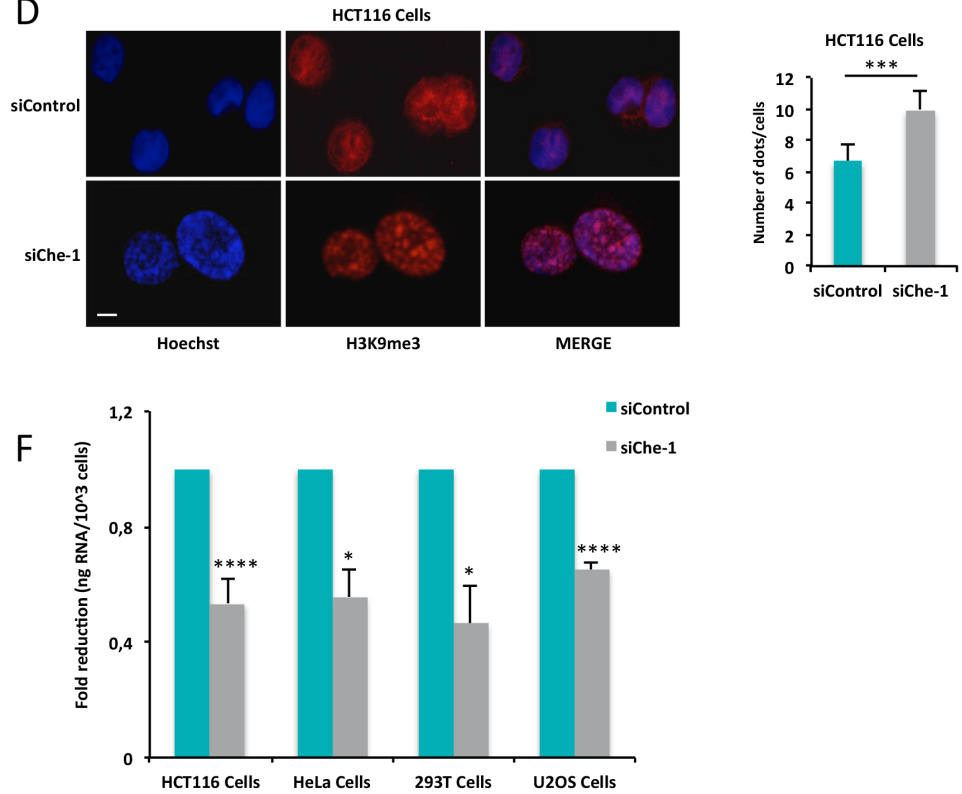

Figure 1

\section{Figure 1}

Che-1 depletion reduces proliferation in several cancer cell lines. A: Cell proliferation analysis (top) and WB analysis of total cell extracts (bottom) from the indicated cell lines transiently transfected with stealth siRNA Control (siControl) or siRNA Che-1 (siChe-1) for 48 hours. Bar plot shows the average of number of cells observed in these experiments $(n=3)$. B: Two images representing nuclear morphology (left), corresponding fluorescence intensity analysis (middle) and WB analysis (right) of HCT116 cells transiently transfected with siControl or siChe-1. Nuclei were visualized by staining with Hoechst dye. Scale bar, $10 \mu \mathrm{m}$. Error bars represent the SD after combining the results of three different experiments. C: Representative WB analysis with the indicated antibodies of nuclear extracts from HCT116 cells transfected as in B. D: Representative immunofluorescence analysis (left) and corresponding fluorescence intensity analysis (right) of H3K9me3 expression in HCT116 cells transfected as in B. Nuclei were visualized by staining with Hoechst dye. Scale bar, $10 \mu \mathrm{m}$. E: Representative WB analysis with the indicated antibodies of total cell extracts from the indicated cell lines and transfected as in A. F: Cell number-normalized quantification of total RNA extracted from the cell lines used in A. Statistical 
significance is indicated by asterisks as follow: ${ }^{*} P<0.05, * \star P<0.01,{ }^{\star} * \star P<0.005, * \star \star \star P<0.001$, n.s. $=$ not significant.

A

Homo Sapiens Mus Musculus Canis Lupus familiaris Macaca Mulatta Pan Troglodytes

C

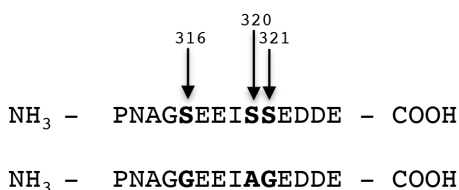

D

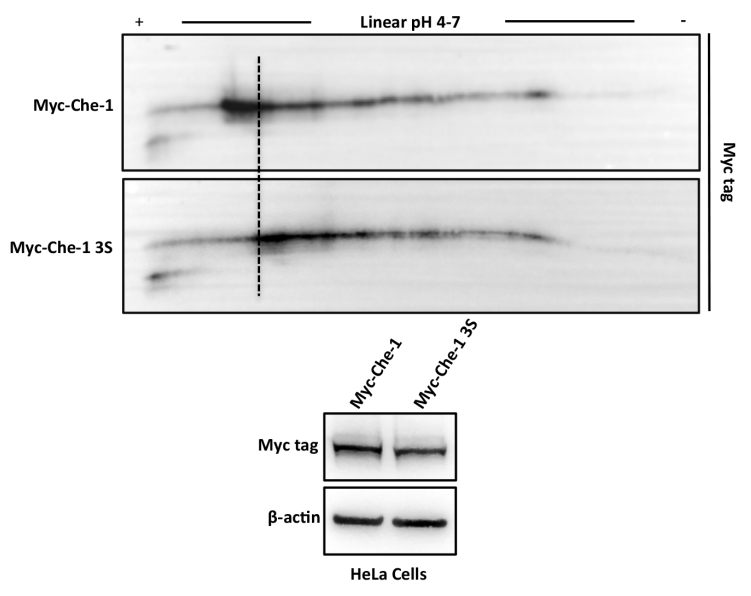

residues $308-325$

LOEELTFOYPDTRYLVDGTKPNAGSEE-ISSEDDELVEFKKOORRRVPAKRKLFMFDYPS LOEELLFOYPDTRH IVNGAKPNTESEE-ISSEDDELVGEKK-KORKAPPKRKLEMEDYYS LOEELLFOYPDTRYLVDGTKPKAESEEEISSEDEELVGEK-KOORRAPPKRKLEMEDYPS LQEELLFQY PDTRYLVDGTKPNAGSEE-ISSEDDELVEEKTQQRRRVPAKRKLEMEDYPS LQEELIFQYPDTRY LVDGTKPNAGSEE-ISSEDDELVEEKKQQRRRVPAKRKLEMEDYP

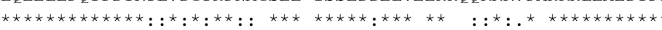

Che-1 wt

Che-1 3S
B

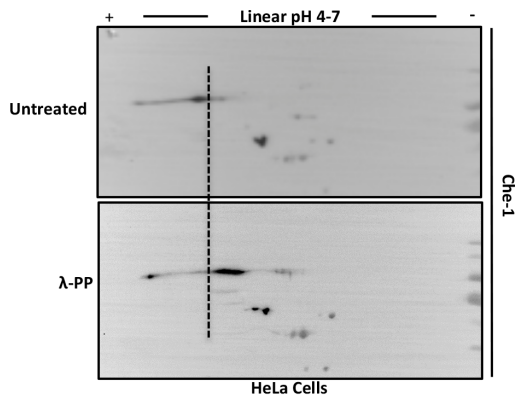

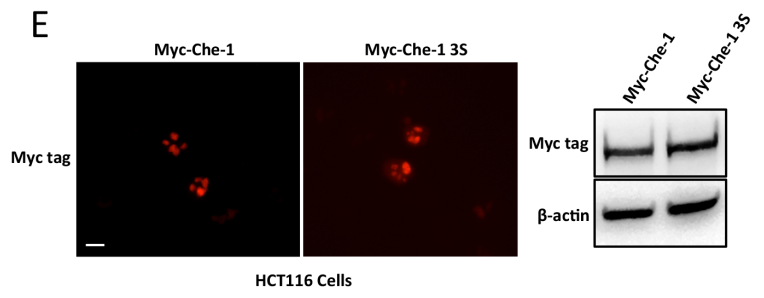

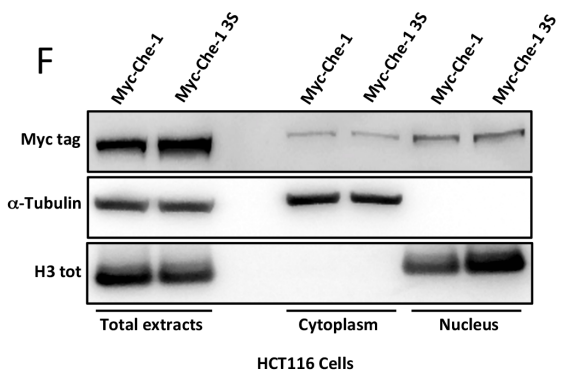

Figure 2

\section{Figure 2}

Che-1 is highly phosphorylated. A: A multiple sequence alignment of five mammalian Che-1 proteins. Below each position of the protein sequence alignment is present a key denoting conserved sites $\left(^{*}\right)$, sites with conservative replacements (:), sites with semi-conservative replacements (.) and sites with nonconservative replacements ( ). B: Total cell extracts from HeLa cells treated or not with $\lambda$-PP (see Methods) were separated onto parallel 2D-Gel electrophoresis. C: Schematic representation of Che-1 point mutations (see Methods) at the indicated sites. D: 2-D gel electrophoresis (top) and representative WB (bottom) of HeLa cells transiently transfected with Myc-Che-1 or Myc-Che-1 3S. E: Representative immunofluorescence images (left) and WB analysis (right) of HCT116 cells transfected with the indicated expression vectors. Scale bar, $10 \mu \mathrm{m}$. F: WB analysis with the indicated antibodies of total, cytoplasmic and nuclear fractions from HCT116 cells transfected as in D. 


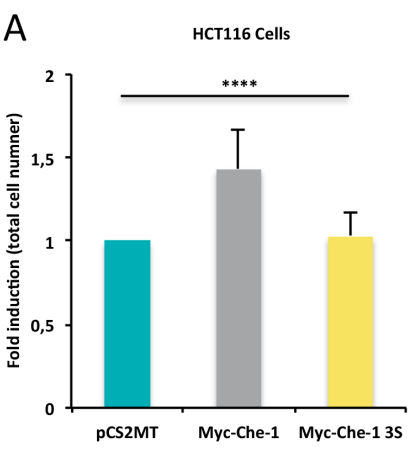

D
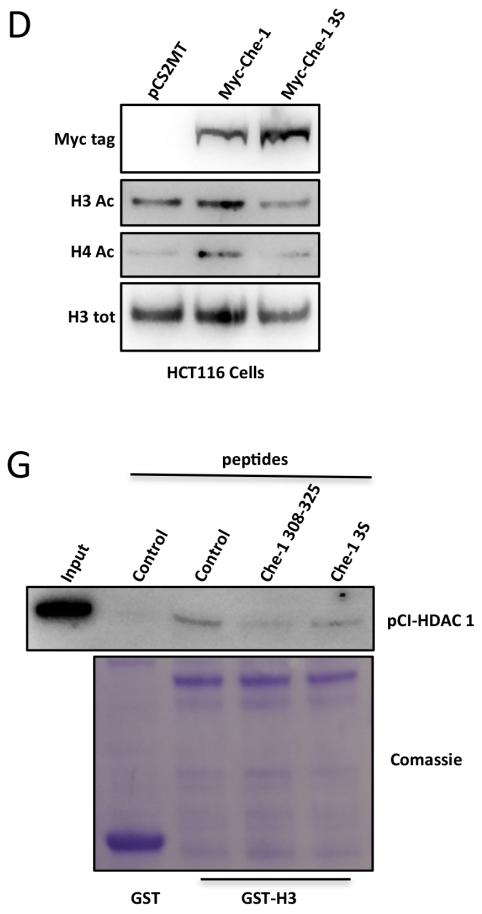

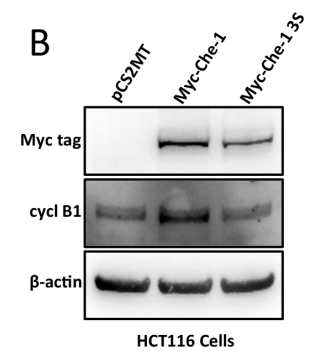

C
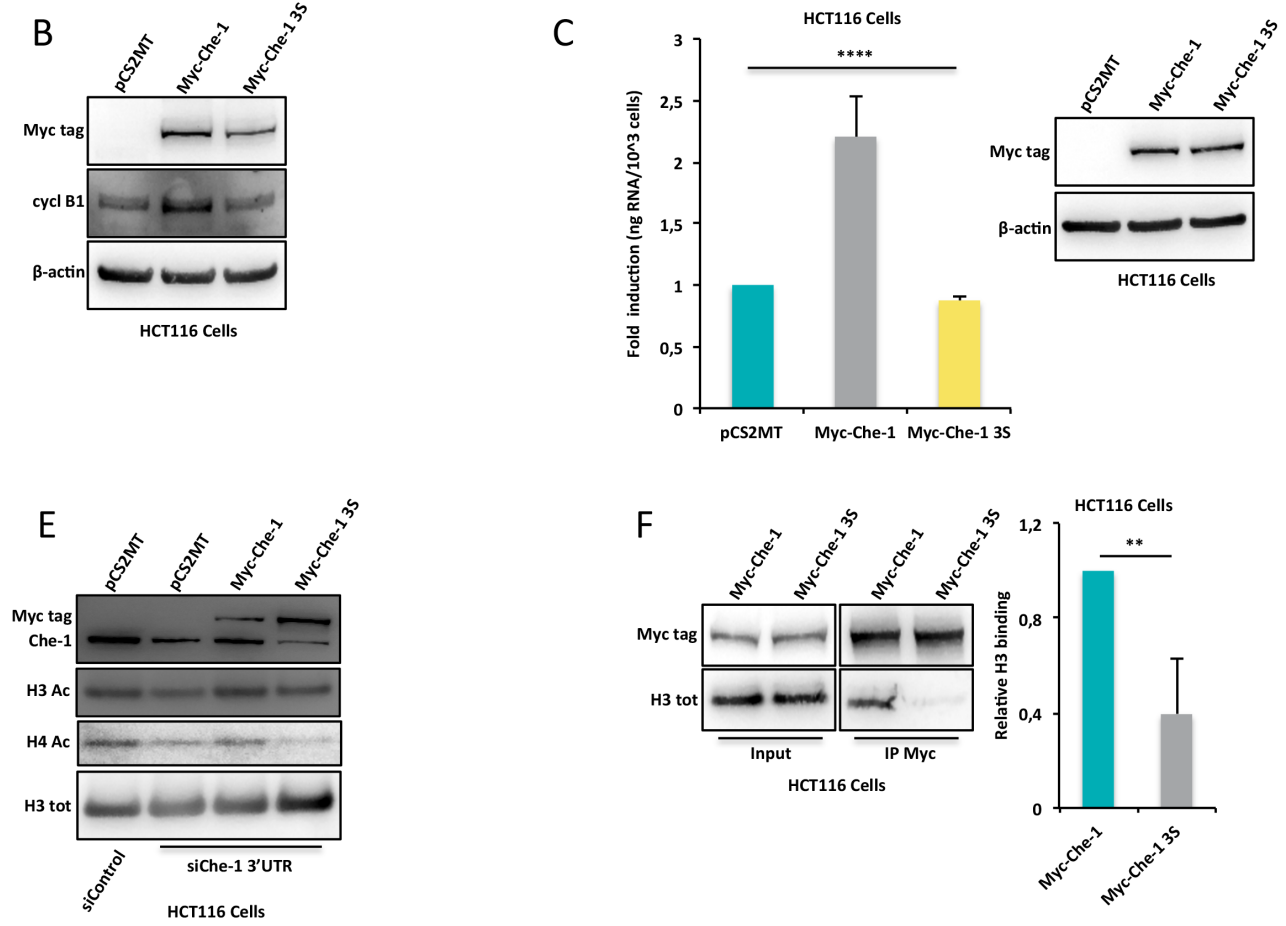
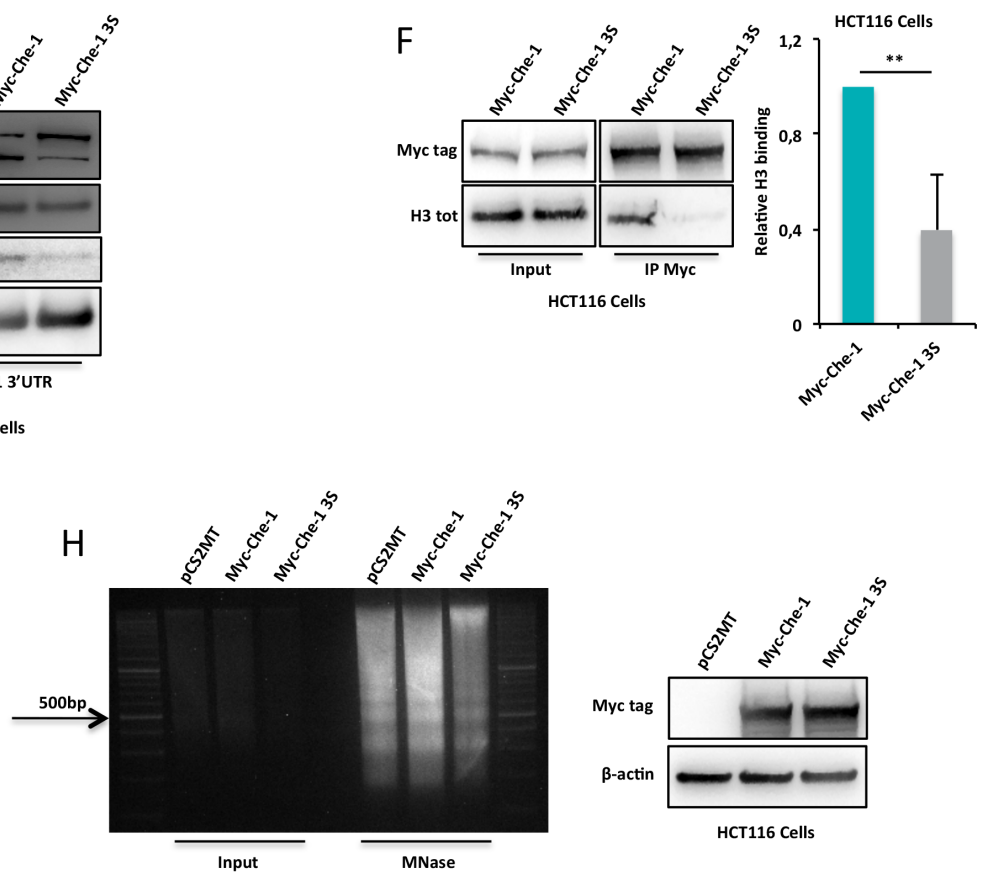

Figure 3

\section{Figure 3}

Che-1 phosphorylation is required for its pro-proliferative ability. A: Cell proliferation analysis of HCT116 cells transiently transfected with Myc-Che-1, Myc-Che-1 3S or control vector (pCS2MT). Bar plot shows the average number of cells observed in these experiments $(n=6)$. B: Representative WB analysis with the indicated antibodies of total cell extracts from HCT116 cells transfected as in A. C: Cell numbernormalized total RNA quantification of the indicated cell line transiently transfected with Myc-Che-1 wt, 3S mutant or control vector. Error bars represent the SD of triplicate experiments $(n=3)$. D: WB analysis with the indicated antibodies of total cell extracts from HCT116 cells transfected as in C. E: WB analysis of total cell extracts of HCT116 cells transfected with siControl or siChe-1 3'UTR alone or in combination with empty vector or with Che-1 expressing vectors (Myc-Che-1 and Myc-Che-1 3S). F: Nuclear extracts from HCT116 cells transiently transfected with Myc-Che-1 wt or 3S mutant, were subjected to IP with antiMyc monoclonal antibody. Immunoprecipitated complexes were then analysed by WB with the indicated antibodies. Input corresponds to $10 \%$ of the nuclear extracts used for IP (left). Relative H3 binding was calculated from three different experiments by densitometry. H3 intensity was normalized to the one of Myc-Che-1 wt or 3S mutant (right). G: WB analysis of GST-pull down experiment conducted using total 
extracts from HCT116 cells over-expressing pCI-HDAC1 incubated with purified GST-H3 fusion protein or control GST agarose beads, in presence or absence of the indicated peptides. GST fusion proteins expression is shown by Comassie blue staining. $\mathrm{H}$ : MNase digestion pattern of nuclei (left) corresponding WB analysis (right) with the indicated antibodies of total cell extracts from HCT116 cells transfected as in A. Statistical significance is indicated by asterisks as follow: ${ }^{*} P<0.05,{ }^{\star} P<<0.01,{ }^{*} * *<0.005,{ }^{*} \star * \star P<0.001$, n.s. = not significant.

\section{A}

Che-1(308-325) D G T K P N A G S E E I S E D D E

SV40 LT

$N$ E E N L F C S E E M P S S D D

C
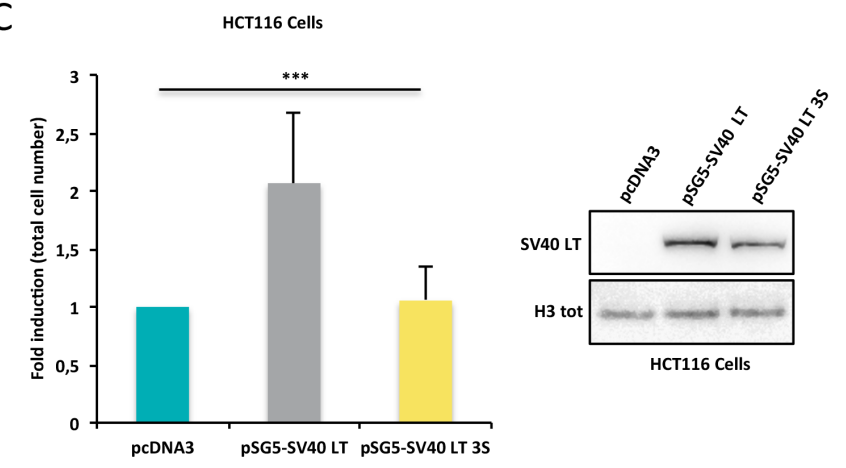

$\mathrm{E}$
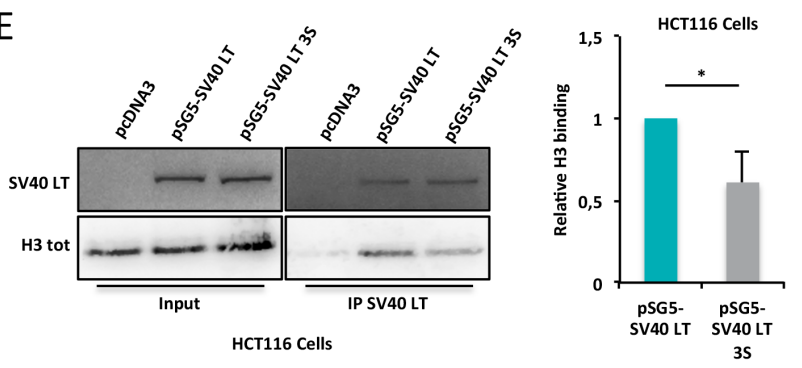

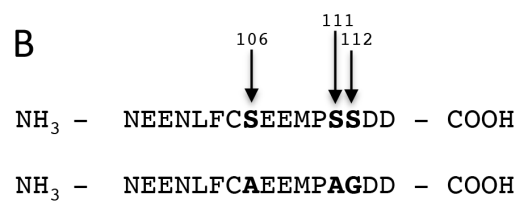

SV40 LT wt

SV40 LT 35
D

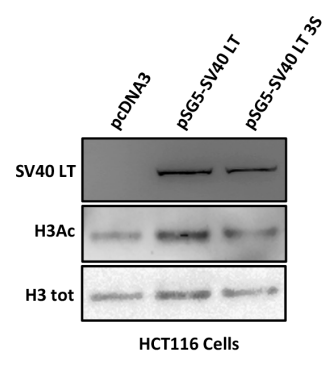

Figure 4

\section{Figure 4}

Che-1 and SV40 Large T antigen display similar functions. A: Sequence alignment of Che-1 and SV40 Large T antigen (SV40 LT) proteins. Conserved serine residues are in red. B: Schematic representation of SV40 LT point mutations (see Methods) at the indicated sites. C: Cell proliferation analysis (left) and relative representative WB analysis (right) of HCT116 cells transfected with PSG5-SV40 LT wt, 3S mutant or empty vector (pcDNA3). Bar plot shows the average number of cells observed in these experiments $(n=3)$. D: WB analysis with the indicated antibodies of total cell extracts from HCT116 cells transfected as in C. E: Nuclear extracts from HCT116 cells transfected as in C and subjected to IP with SV40 antibody. Immunoprecipitated complexes were then analysed by WB with the indicated antibodies. Input 
corresponds to $10 \%$ of the nuclear extracts used for IP (left). Relative H3 binding was calculated from three different experiments by densitometry. H3 intensity was normalized to the one of SV40 wt or 3S mutant (right). Statistical significance is indicated by asterisks as follow: ${ }^{\star} P<0.05,{ }^{*} P<0.01,{ }^{*} * \mathrm{P}<0.005$, $\star \star \star \star P<0.001$, n.s. $=$ not significant.

A

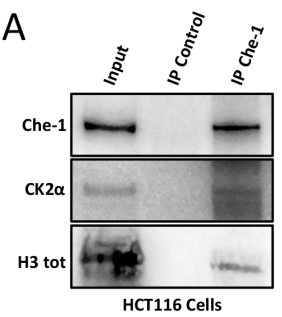

D

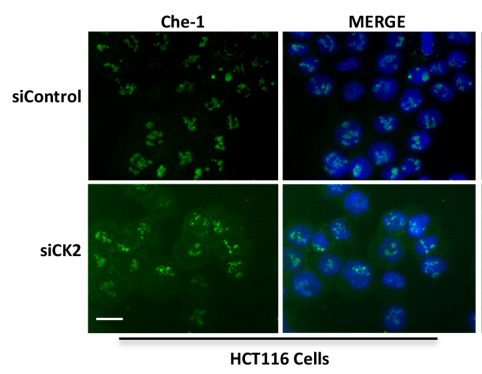

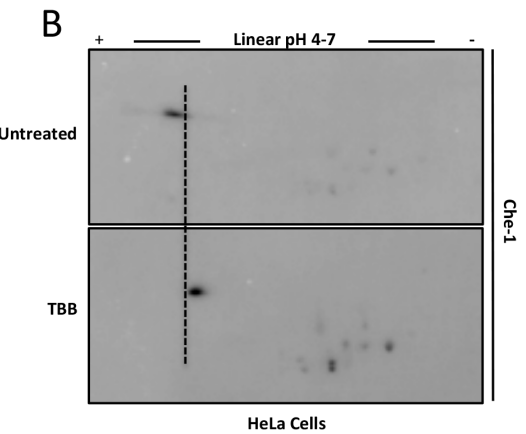

HeLa Cells
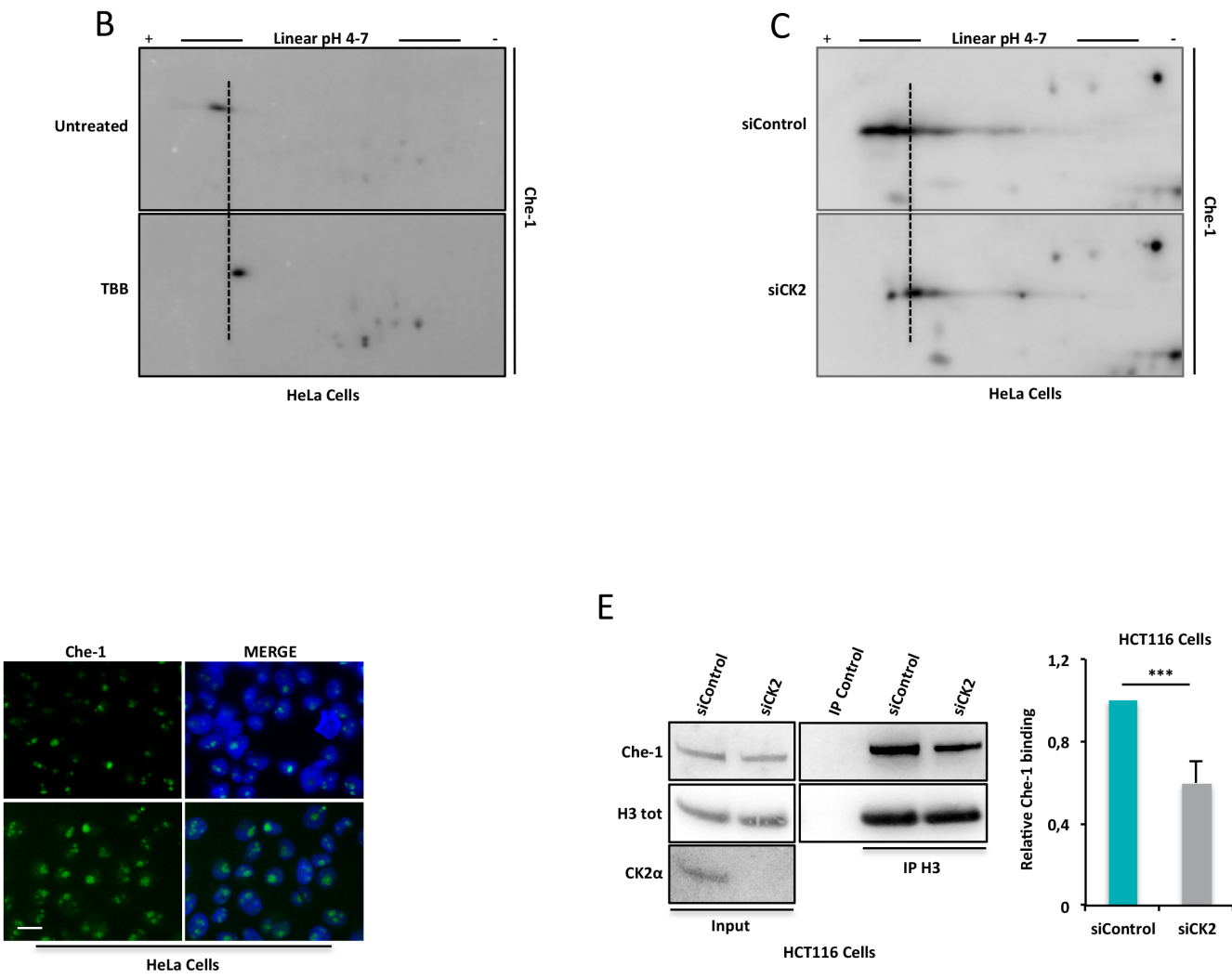

$\mathrm{E}$
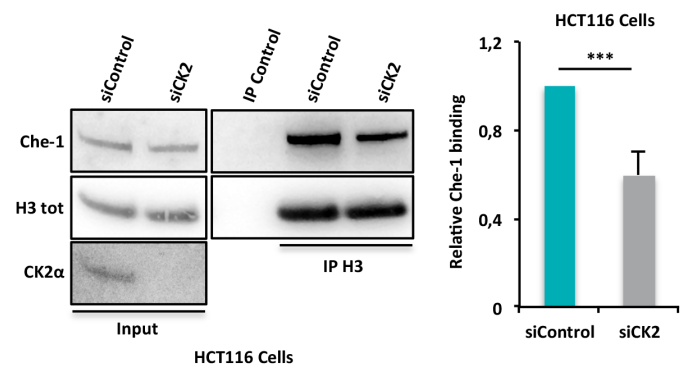

Figure 5

\section{Figure 5}

CK2 phosphorylates Che-1. A: Nuclear extracts from HCT116 cells subjected to IP with Che-1 antibody. Immunoprecipitated complexes were then analysed by WB with the indicated antibodies. Input corresponds to $10 \%$ of the nuclear extracts used for IP. B and C: 2D-Gel electrophoresis of total cell extracts from HeLa cells treated or not with $80 \mu \mathrm{M}$ TBB for 4 hours (B) or transfected with siControl or siCK2 (C). D: Representative immunofluorescence analysis of Che-1 expression in the indicated cell lines transiently transfected with siControl or siCK2. Scale bar, $10 \mu \mathrm{m}$. E: Nuclear extracts from HCT116 cells transiently transfected as in D and subjected to IP with $\mathrm{H} 3$ antibody. Immunoprecipitated complexes were then analysed by WB with the indicated antibodies (left). Input corresponds to $10 \%$ of the nuclear extracts used for IP. Relative Che-1 binding was calculated from three different experiments by densitometry. Che1 intensity was normalized to the one of $\mathrm{H} 3$ (right). Statistical significance is indicated by asterisks as follow: ${ }^{*} P<0.05,{ }^{*} P<0.01,{ }^{*} * \mathrm{P}<0.005,{ }^{*} * * \mathrm{P}<0.001$, n.s. $=$ not significant. 


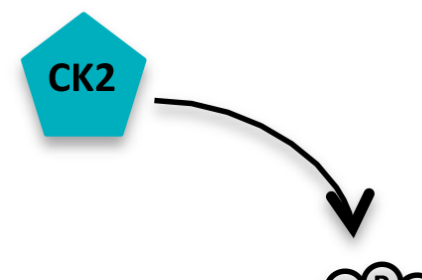

\section{HDACs} PPD
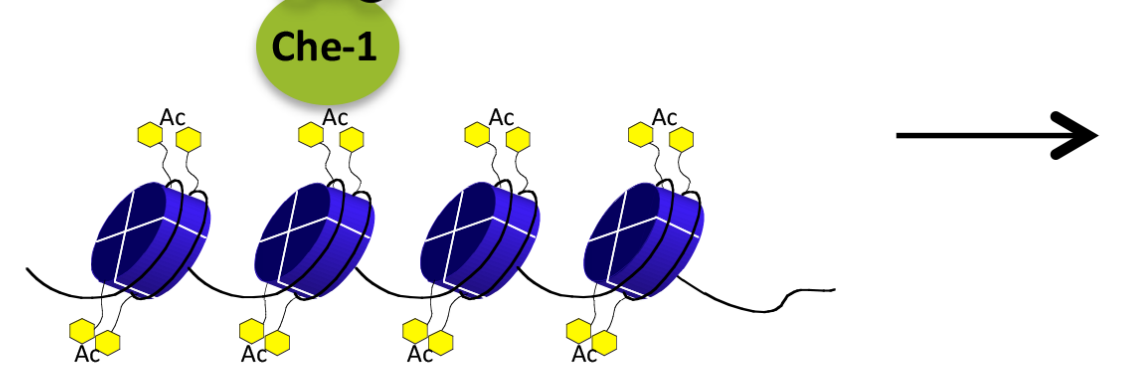

\section{Cancer cell proliferation}

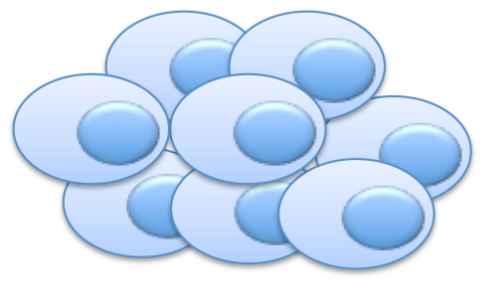

\section{Cancer cell proliferation}

\section{Che-1}
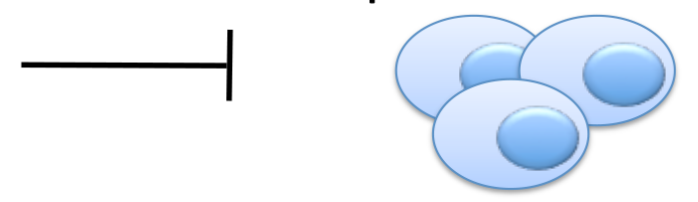

\section{Figure 6}

Figure 6

Role of CK2 phosphorylation in regulating Che- 1 functions. Phosphorylation of Che- 1 by CK2 is required for displacing HDACs from chromatin and sustaining cancer cell proliferation.

\section{Supplementary Files}

This is a list of supplementary files associated with this preprint. Click to download.

- AdditionalFile1.pdf 